\title{
In Case You Missed It: Business News from the Field
}

\section{themagazine Put to the Test \\ skarn and more copper-rich styles of mineralization developed at depth.}

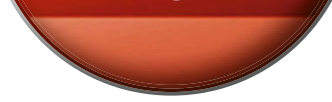

Munich, Germany: Researchers at the

Munich University of Applied Sciences tested a new additive manufacturing process for orbiting spacecraft in collaboration with the European Space Agency. The team developed a $3 \mathrm{D}$ printer that extrudes liquid photopolymer, applies ultra-violet light to harden structures quickly, and moves the print head three-dimensionally rather than in a layer-by-layer traditional movement. Testing took place on parabolic flights. Components printed in spacecraft may be tailored to their purposes in comparison to Earth-made counterparts that must be oversized and built to withstand the forces of rocket launch.

or press release to

Kaitlin Calva,

JOM Magazine

Managing Editor, at kcalva@tms.org for consideration.

\section{EMX and Esan Partner in Turkish Mine} Vancouver, Canada: EMX Royalty Corporation with operating partner Esan Eczacibaşi Endüstriyel Hammaddeler San ve Tic AŞ began construction on a leadzinc-silver royalty property in northwestern Turkey. Commercial production may start as early as the fourth quarter of 2021. EMX acquired the project's mineral rights via its exploration programs, and then sold the

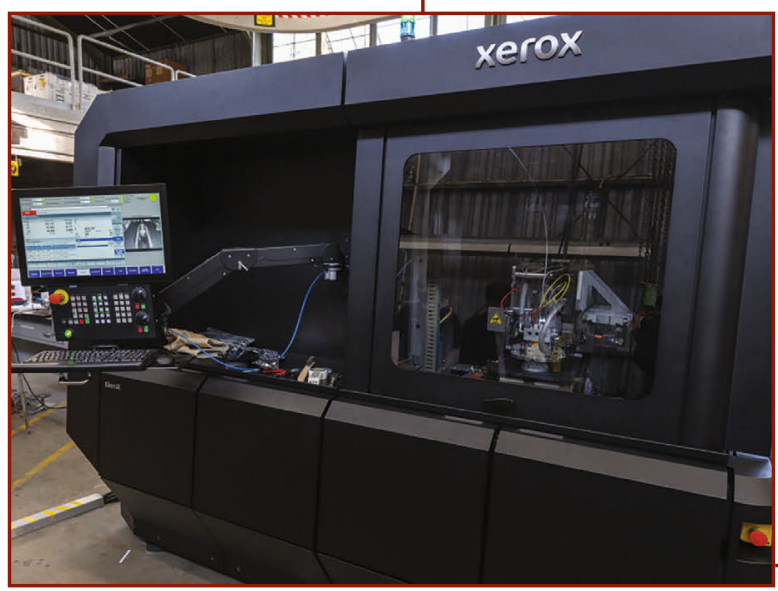
property while retaining a $4 \%$ net smelter return. The property is situated in Balya mining district where there are extensive zones of carbonate replacement style lead-zinc-silver mineralization in addition to

Monterey, California, USA: Xerox Corporation deployed ElemX 3D printer for research activities at the U.S. Naval Postgraduate School. ElemX is one of the first products to employ a production methodology called liquid metal jet printing (LMJP). University trials found LMJP up to 10 times faster and one-tenth the cost of prevailing additive manufacturing methods. Liquid metal jet printing may also lead to a $30 \%$ or greater increase in overall tensile strength. The printer could facilitate the mass production of parts for defense, aerospace, heavy equipment, and oil and gas applications in the future. (Photo by Petty Officer 3rd Class Leonard Weston, Naval Postgraduate School.)

\section{ARM Begins Platinum Project Johannesburg, South Africa: African Rainbow Minerals (ARM), a diversified mining company, is moving forward on the Merensky reef project at the Two Rivers platinum group metals (PGM) mine, near Burgersfort, South Africa. The project will produce 182,000 six-element PGM ounces, 1,600 tonnes of nickel, and 1,300 tonnes of copper a year. Two Rivers is a joint venture between ARM, at 51\%, and Impala Platinum Holdings Limited, at 49\%.}

\section{Steel Dynamics Readies New Mill \\ Fort Wayne, Indiana, USA: Steel} Dynamics Inc. (SDI) plans to begin operations this summer at its new $\$ 1.9$ billion flat-rolled steel mill in Sinton, Texas, as the pandemic has not impacted construction. The new state-of-the-art electric-arc-furnace flat roll steel mill is expected to have an annual production capacity of approximately three million st and is strategically located within the southwestern U.S. and Mexican markets. At least three SDI customers have committed to locating operations on the mill's campus, representing one million tons of annual processing and consumption capacity.

\section{New Magnesium Alloy \\ Thwarts Corrosion}

Geesthacht, Germany: Scientists at the Helmholtz-Zentrum Geesthacht Centre for Materials and Coastal Research created an alloy with pure magnesium and very small amounts of calcium that achieved an exceptionally low corrosion rate. The calcium reduces the cathodic water reduction kinetics, allows the development of a protective surface film, and stabilizes impurities within the alloy. The alloy was comparable to stainless magnesium in corrosion resistance. The discovery may impact the light metal's use in industry, where magnesium alloys are valued for automotive, aerospace, electronics, biomedical, and energystorage applications. 